\title{
Mapping additional streamflow decline due to shifts in catchment response during the Millennium Drought
}

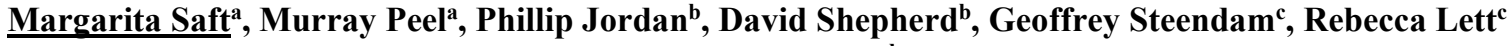 \\ and Tim Peterson ${ }^{\text {d }}$ \\ ${ }^{a}$ Department of Infrastructure Engineering, University of Melbourne, Australia, ${ }^{b}$ Hydrology and Risk \\ Consulting $(H A R C)^{c}$ Victorian Department of Environment, Land, Water and Planning ${ }^{d}$ Department of Civil \\ Engineering, Monash University, Australia \\ Email: margarita.saft@unimelb.edu.au
}

\begin{abstract}
The Millennium drought has been challenging in many ways including scientifically. It is widely reported that runoff declines were larger than observed during previous droughts of similar magnitude but shorter duration. It has been shown that catchments shifted their hydrologic response to rainfall and this has been attributed to internal changes in catchment systems rather than meteorological factors. In other words, there was an emergent behaviour during the drought that was not experienced during the prior hydrologic record. This emergent behaviour, while widespread, affected different catchments differently. While some catchments exhibited a runoff decline that was two or more times larger than during previous dry years with similar rainfall decline, other catchments did not change their response and behaved similarly to other dry years. Given that the future climate in south-eastern Australia is expected to be drier, it would be useful to understand where the change in hydrologic response was more prominent and where the hydrologic response was more stable and resilient during the Millennium drought. While there is no guarantee that longer shifts in climate will not result in further changes in catchment response, it is still likely that the pattern of change will resemble the pattern encountered during the Millennium drought.
\end{abstract}

Here we characterise the additional runoff decline due to the shift in hydrologic behaviour and map it across Victoria on a $0.05^{\circ}$ grid including ungauged locations. We use a large dataset of natural and semi-natural catchments to construct a predictive model for additional streamflow decline which is then applied to the state of Victoria. First, we separate runoff decline into "expected" streamflow decline (runoff decline in line with previous dry years with similar rainfall) and additional streamflow decline which we quantify across study catchments with long-term streamflow records. Then we use multi-model inference based on information theory to select a set of most informative predictors and construct a multivariate statistical model. This approach is particularly suitable for our dataset as we work with cross-correlated and potentially interacting predictors. The resulting model explains $\sim 71 \%$ of the variance in the additional streamflow decline based on both catchment characteristics and meteorological anomalies of the drought. Once the suitable model is selected, we apply it across Victoria (except the arid north-west region) to create a map of additional streamflow decline. The fine resolution of the map allows the local spatial patterns, not present in earlier catchment-based studies, to be seen. The state-wide application provides estimates of the additional streamflow decline across the region and not tied to the study catchments for the first time.

The resulting map indicates which areas in Victoria are more resilient and which are less resilient to the shifts in hydrological response during prolonged periods of predominant dry conditions. While based on the Millennium drought, this map is likely to be applicable to future climatic shifts because the multivariate statistical modelling shows a strong relationship with catchment properties that will persist over time. While future shifts might be more widespread or severe, the Millennium drought gives us a useful new baseline of expected hydrologic response. More work is required to understand and quantitatively model the mechanisms of hydrologic shift, and while such models are not available this map can be used to gauge the potential of future hydrologic shifts under similar conditions.

Keywords: Hydrological shift, multi-year drought, streamflow, information theory, catchment hydrology 
Saft et al., Mapping additional streamflow decline due to the shifts in catchment response during the Millennium Drought

\section{INTRODUCTION}

It is widely acknowledged that streamflow declines during the Millennium drought (1997-2009) were significantly larger than expected from the rainfall decline alone (Chiew et al., 2014; Peterson et al., 2021; Potter and Chiew, 2009; Saft et al., 2015). The estimated return period for the hydrological drought was several times larger than the return period of the meteorological drought (Gallant and Gergis, 2011; Hunt, 2009; Potter et al., 2010). Hydrologic model simulations of this drought systematically overestimated the streamflow (Coron et al., 2012; Fowler et al., 2020; Saft et al., 2016a). These issues were related to (or reflected in) a downward shift in the rainfall-runoff relationship (Saft et al., 2015). That is, for a given rainfall during the Millennium drought, streamflow decline was amplified compared to a pre-drought year with a similar rainfall. This disparity between expected and observed streamflow increases the challenge of managing already low water resources during an extended dry period.

While the drought was observed across most of south-eastern Australia, including across Victoria, the severity of the drought varied spatially and depending on the metric used. The rainfall anomaly (in \%) varied only slightly across Victoria, while the runoff anomaly had a prominent spatial pattern with the western parts of the state experiencing larger \% runoff anomaly (Chiew et al., 2014). The spatial pattern of shifts in rainfall-runoff relationships was inconsistent. While western catchments were more prone to shifts in hydrologic response than eastern catchments, the degree of spatial heterogeneity was high with neighbouring catchments often showing different responses, so it has been argued and shown that catchment endogenous properties shaped hydrological response during the multiyear drought (Saft et al., 2015).

The Millennium drought provides both motivation and data to understand and evaluate catchment response to prolonged drying. Projections of future climate in south-eastern Australia are similar to the Millennium drought climate (Chiew et al., 2011), which gives us an option to use the Millennium drought as a guide for what the future may hold. In this light, estimates of additional streamflow decline accounting for shifts in the rainfallrunoff relationship can be an improvement on conventional modelling-based methods that lack explicit accounting for the rainfall-runoff shifts. It has been shown that implicit accounting for changes in hydrological behaviour, e.g. adding the Millennium drought to the model calibration period, usually does not provide a significant improvement in simulating the changed response (Trotter et al, 2021). While the impacts of longer climatic shifts may be beyond those observed during the Millennium drought, this period can still serve as a useful baseline. The aims of this study are: (1) to characterise the range and spatial organisation of additional streamflow decline (i.e. streamflow decline exceeding expectations based on the rainfall decline and hydrologic behaviour during previous droughts); and (2) to develop a state-wide map of this additional streamflow decline during the Millennium Drought including areas where local streamflow data are not available. To the best of our knowledge, the map we present here is the first spatially continuous map of the hydrological shift observed during the Millennium Drought.

\section{METHODS}

\subsection{Definition of additional streamflow decline}

Here we focus on the proportion of streamflow decline in excess of the expected streamflow response to a given rainfall decline (Figure 1). We use annual rainfall-runoff relationships to characterise the "normal" or expected streamflow response to a given rainfall. Consistent deviation from the established precipitation-streamflow relationship represents a shift in catchment response and therefore an additional streamflow decline not explained by the annual precipitation deficit.

We distinguish between streamflow decline typical for dry years ("expected") and streamflow decline due to the shift in rainfall-runoff relationship and focus on the latter. We fit rainfall-runoff relationships allowing for a potential shift during the drought, in line with Saft et al. (2016b). For each drought year, we estimate expected runoff using both pre-drought and drought relationships given the rainfall of that year. The difference between the two estimates represents the part that is independent of annual

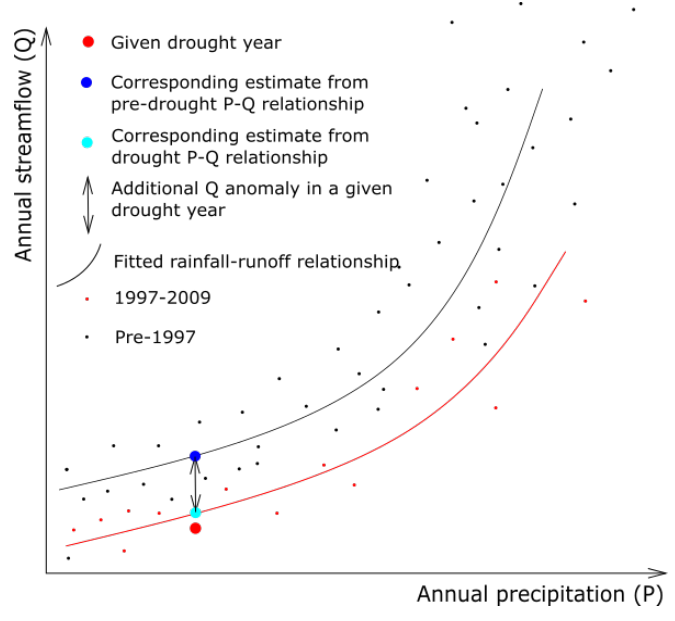

Figure 1. Additional streamflow decline illustrated with a rainfall-runoff relationship in an example catchment. 
Saft et al., Mapping additional streamflow decline due to the shifts in catchment response during the Millennium Drought

rainfall and therefore the additional streamflow decline. The overall additional streamflow decline during the Millennium drought is then calculated as the average of the additional streamflow decline for the 13 drought years expressed as a percentage of the pre-drought mean runoff. Note that the metric we use here is different from the magnitude of shift used earlier (e.g. Saft et al. 2016) in several ways including expressing the difference between expected and observed streamflow as a \% of pre-drought streamflow (and not expected drought flow). Drought is defined as 1997-2009 water years (March to February) inclusive in all catchments.

\subsection{Multi-model inference approach}

Table 1. The drivers and impacts

\begin{tabular}{|c|c|}
\hline Abbreviation & Predictor \\
\hline \multicolumn{2}{|c|}{ Topographic parameters } \\
\hline areasqrt & Catchment area (square root) \\
\hline slope & Mean slope \\
\hline elev & Mean elevation \\
\hline elevstd & Elevation standard deviation \\
\hline above1400 & $\%$ area over $1400 \mathrm{~m}$ elevation \\
\hline \multicolumn{2}{|c|}{ Subsurface storage parameters (map based) } \\
\hline dtgwt & Depth to groundwater \\
\hline uath & Unconfined aquifer thickness \\
\hline regolog & Regolith depth (log) \\
\hline fract & $\%$ fractured rock \\
\hline \multicolumn{2}{|c|}{ Soil parameters (map based) } \\
\hline soild & Soil depth \\
\hline awc & Available water capacity \\
\hline bdw & Bulk density \\
\hline clay & Clay content \\
\hline \multicolumn{2}{|c|}{ Vegetation and human impact parameters (map based) } \\
\hline fc2018 & Forest cover \\
\hline fec & Forest cover change \\
\hline plantat & Plantations \\
\hline fdva & Farm dam volume / Catchment area \\
\hline \multicolumn{2}{|c|}{ Hydroclimatic signatures } \\
\hline hi & Mean annual aridity index (P/PET) \\
\hline pet & Mean annual potential ET \\
\hline temp & Mean annual temperature \\
\hline p10sump & Storminess $(\mathrm{P}>10 \mathrm{~mm} /$ total $)$ \\
\hline pcv & $\mathrm{Cv}$ of annual precipitation \\
\hline seas & Seasonality index \\
\hline sdlmft & Minimum flow threshold \\
\hline \multicolumn{2}{|c|}{ Drought characteristics } \\
\hline p_dr & Precipitation anomaly (\%) \\
\hline pet_dr & Potential ET anomaly (\%) \\
\hline seas_dr & Seasonality anomaly (\%) \\
\hline p10sump_dr & Storminess anomaly (\%) \\
\hline pcv_dr & $\begin{array}{l}\mathrm{Cv} \text { of annual precipitation anomaly } \\
(\%)\end{array}$ \\
\hline $\begin{array}{l}\text { smr_dr, atmn_dr, } \\
\text { wntr_dr, spr_dr }\end{array}$ & $\begin{array}{l}\text { Summer, autumn, winter, and spring } \\
\text { precipitation anomaly }(\%)\end{array}$ \\
\hline temp_dr & Temperature anomaly (\%) \\
\hline
\end{tabular}

The multi-model inference approach adopted here closely follows the approach described in Saft et al. (2016b) which in turn was based on the method of Burnham and Anderson (2002).

The general procedure for multi-model inference includes optimizing the full set of statistical models with all possible combinations of predictors and evaluating the models using information criteria. Here we use AICc (consistent Akaike information criterion (Bozdogan, 1987)) and CAIC (complete Akaike information criterion (Hurvich and Tsai, 1989)). The information criterion distances (i.e. differences with the best performing model) and model weights are calculated for each model, and the sum of the model weights containing a given predictor (called Proportion of Evidence, PoE) represents the informational value of a given predictor (Burnham and Anderson, 2002). Given the high number of possible predictors, we repeat the procedure twice. First, we run $\sim 1.7$ million combinations of 34 predictors in multiple regression models of limited complexity (up to 6 predictors per model). The proportion of evidence, PoE, is calculated as per the procedure above and the 12 least informative predictors are removed from the analysis. Next, all possible combinations of better-performing 22 predictors are run (up to 22 predictors per model, 4.2 million models). We analyse results combining information criteria-based PoEs, adjusted $\mathrm{R}^{2}$ (Wang and Thompson, 2007), and statistical significance of regression multivariate coefficients.

We used a comprehensive list of predictors (same as in Saft et al., 2021) to represent biophysical catchment properties (including topography, geology and hydrogeology, soils, vegetation, human impacts such as farm dams, and long-term pre-drought climatic means), and drought meteorological anomalies. The full list of predictors is presented in Table 1. All predictors containing suffix “_dr" represent anomalies during the drought relative to the pre-drought average of a given characteristic. 
Saft et al., Mapping additional streamflow decline due to the shifts in catchment response during the Millennium Drought

\section{RESULTS}

\subsection{Observed additional streamflow decline}

Figure 2 shows the map and histogram of additional streamflow decline across the study catchments. The additional streamflow decline ranged between 0 and $40 \%$ of the mean pre-drought streamflow. Catchments with no or smaller additional decline (i.e. streamflow decline in line with historical response) cluster in high elevation parts of eastern Victoria, while large additional decline is typical in western Victoria, which is in line with the earlier research (Fowler et al., 2020; Saft et al., 2016b).

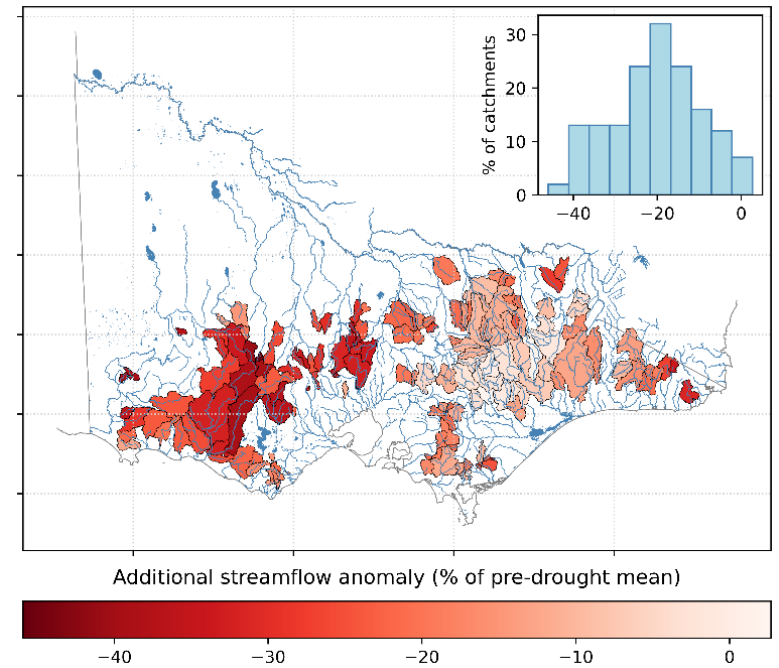

Figure 2. The map of observed additional streamflow decline in study catchments.

\subsection{Multi-model inference and model selection}

Proportion of evidence (PoE) results from the multi-model inference analysis are presented in Figure 3.
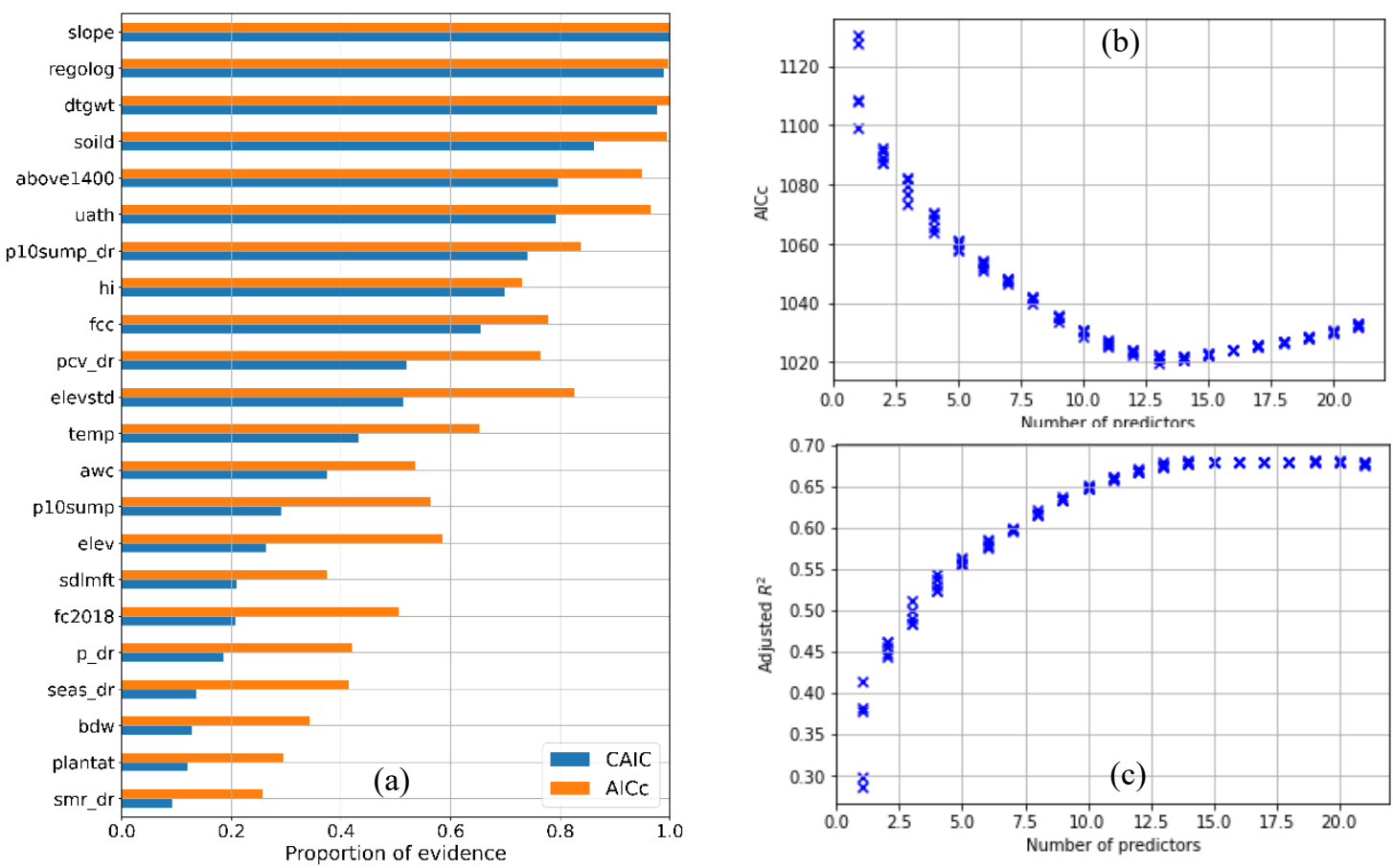

Figure 3. Multi-model inference results: (a) Proportion of evidence per predictor in the extensive search (b) AICc scores and (c) Adjusted $\mathrm{R}^{2}$ for 5 best models with a given number of predictors per model. 
Saft et al., Mapping additional streamflow decline due to the shifts in catchment response during the Millennium Drought

Multi-model inference allows us to distinguish between more informative and hence useful predictors and predictors which do not add significant value to the models. The strengths of this method include accounting for some interactions between predictors, e.g. when two or more predictors add value together, and detecting more informative predictors even when metrics are closely related, i.e. cross-correlation is high. Slope, regolith depth, depth to groundwater, soil depth, snow-impacted area, and unconfined aquifer thickness dominate the results scoring proportion of evidence of close to 0.8 or higher for both information criteria used.

The level of complexity of the resulting statistical model was selected via identifying the optimal number of predictors based on the analysis of curves of best models with any given number of predictors (Figures $3 \mathrm{~b}$ and $3 \mathrm{c})$. AICc was minimised at, and adjusted $\mathrm{R}^{2}$ plateaued after, $\sim 13$ predictors. Therefore, we expect our resulting model to have $\sim 13$ predictors. Three sets of the 100 best performing models according to AICc, CAIC, and adjusted $\mathrm{R}^{2}$ were selected, checked for statistical significance of every predictor, and cross-compared. We identified the model with consistently high performance across the three sets, which was the top all-significant model for AICc and adjusted $\mathrm{R}^{2}$ and in the top 10 all-significant models according to CAIC.

The resulting model (parameters and their coefficients) is as follows (see Table 1 for the abbreviations):

Additional streamflow decline $(\%$ of the average pre-drought streamflow $)=$

$=-2.393 *$ awc $-38.382 *$ soild $+1.33 *$ temp $+0.023 *$ elevstd $+0.029 *$ uath $+17.558 *$ hi $-29.5 *$ fcc $+0.11 *$ pcv_dr

$-0.417 *$ p10sump_dr $-0.591 *$ dtgwt $+42.536 *$ above $1400+12.109 *$ regolog $+2.347 *$ slope +7.749

This model explains $\sim 71 \%$ of the variance in additional streamflow decline observed across study catchments.

\subsection{Modelled additional streamflow decline}

The multivariate model (Eq. 1) was applied across Victorian winter-fill sustainable diversion limit catchments (Voorwinde et al., 2003) and then rasterised to a $0.05^{\circ}$ grid to produce a map of additional streamflow decline across Victoria (Figure 4). Figure 4 provides useful information about areas where long-term local streamflow data are not available. For many of the gauged catchments, it provides information at finer spatial resolution than the map in Figure 2. We can see additional details both within our study catchments and outside, e.g. spatial variability patterns in Gippsland.

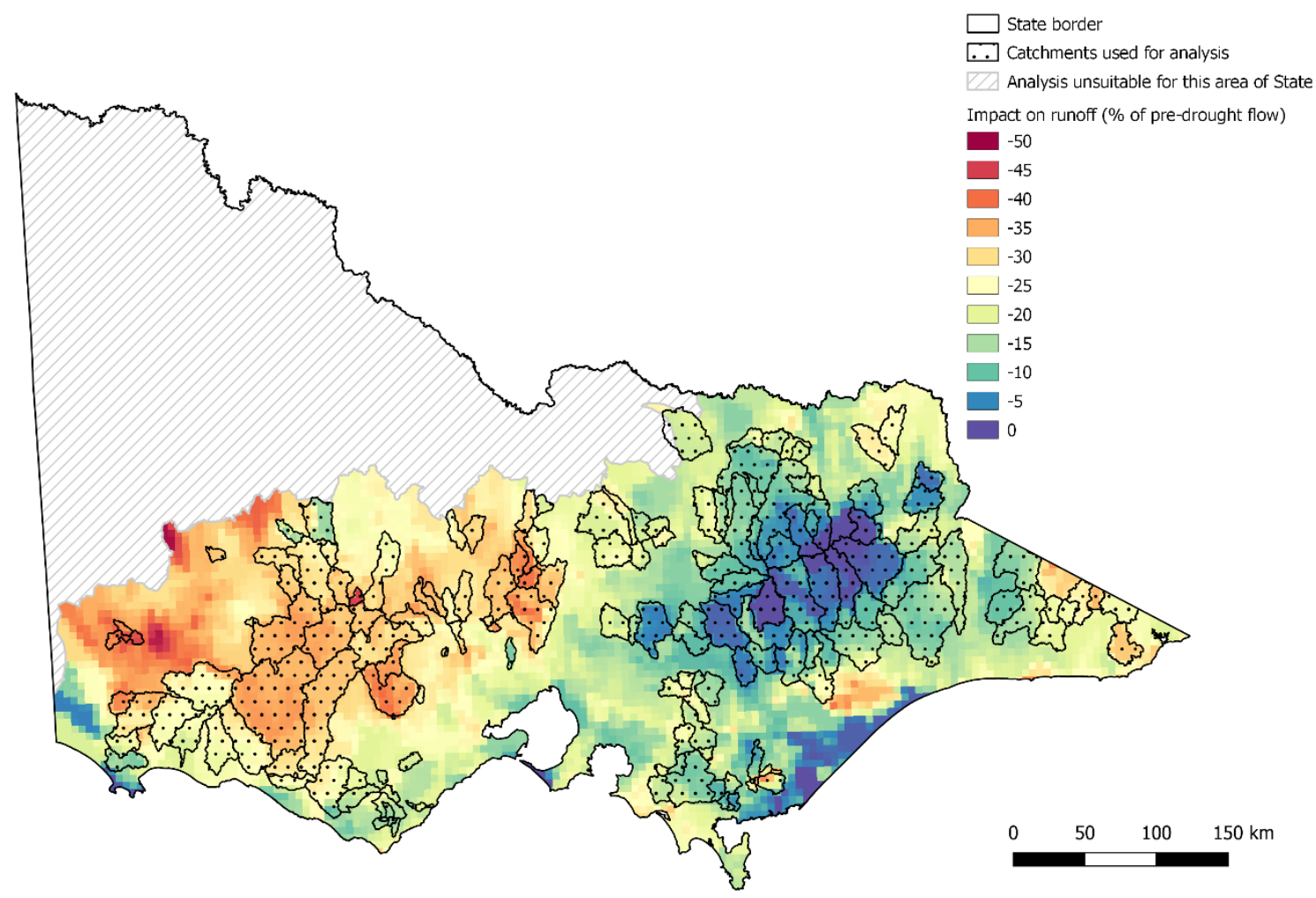

Figure 4. Map of the additional streamflow decline not explained by rainfall decline during the Millennium drought (expressed as a \% of pre-drought mean streamflow) 
Saft et al., Mapping additional streamflow decline due to the shifts in catchment response during the Millennium Drought

The overall spatial pattern is, unsurprisingly, similar to the catchment-scale observations-based map. The degree of correspondence between catchment observations (Figure 2) and the map is high, giving confidence in method applicability. Note, this is not an interpolation-based map, so the modelled surface does not have to intersect the observations it is based on. North-western Victoria was excluded from the application of this analysis due to irrigation areas with flow regulation or natural conditions well outside (i.e. higher aridity) the conditions the model was developed in.

\section{DISCUSSION}

Of the 13 variables in the selected model, only two relate to the properties of the Millennium Drought (changes in standard deviation annual rainfall and in the proportion of rainfall falling on days with $>10 \mathrm{~mm}$ rainfall). Most variables relate to long-term properties of the catchment related to topography (slope, elevation standard deviation, and $\%$ area over $1400 \mathrm{~m}$ elevation), sub-surface storage (unconfined aquifer thickness, depth to groundwater and regolith depth), soil (available water capacity and soil depth), and hydroclimate (temperature and aridity index, P/PET), while only one relates to vegetation and human impact (change in forest area, i.e. deforestation and reforestation). This confirms that additional streamflow decline is shaped by catchment properties rather than drought metrics or human impacts on the catchment. Note that the farm dam variable did not feature in the selected model or the top 22 variables in the multi-model inference.

This analysis is based on natural and semi-natural catchments with no significant artificial alterations of the flow (reservoirs volume, flow extractions). These were limited to a maximum of $5 \%$ of the mean annual runoff. Major irrigation districts were also avoided, and forest area changes were $<10 \%$ in $\sim 90 \%$ of the catchments. The map covers areas with major dams, irrigation, deforestation, plantations, extractions, and diversions. For these areas, the user should be aware that local artificial impacts on the flow are not accounted for by the statistical modelling presented here and the map only represents the additional streamflow decline as if the streamflow was not externally altered. Therefore, caution is required in interpreting the map in areas where human impact on the flow is significant, e.g. irrigation regions.

Caution is further recommended when interpreting the extra streamflow decline metric we used. Additional streamflow decline is expressed as a $\%$ of the pre-drought mean. However, the rainfall during the drought was significantly below the long term mean hence it does not provide any information on how large or small the "unexpected" decline due to the hydrological shift is compared to the "expected" decline due to low rainfall, or what proportion of total streamflow the additional decline constitutes.

It remains uncertain how representative are the shifts in hydrologic response observed during the Millennium drought for the post-drought catchment response and hydrologic response to climate change. After the drought, some catchments have shifted back to the pre-drought rainfall-runoff relationship (i.e. recovered) while other catchments continued to produce significantly less streamflow for a given annual rainfall than prior to the drought even 7 years after the drought had finished (Peterson et al., 2021). For the catchments and regions which remain in a shifted state, the recovery path and even a possibility of recovery remains unknown as well as a possibility of further transition to even larger additional streamflow decline. However, since the additional streamflow decline did not show dependency on rainfall, temperature, or PET anomalies during the drought, and the rainfall decline ranged between $6 \%$ and $25 \%$ in our study catchments, we argue that the presented model is likely to be a reasonable approximation for a wide range of predominantly drier future conditions.

The map is indicative of potential additional streamflow decline where the gauged data are not available provided the flow has not been significantly altered artificially. However, if gauged data of sufficient length are available to construct a local rainfall-runoff relationship, using local data is preferable to using the map.

\section{CONCLUSIONS AND RECOMMENDATIONS}

Here we presented the first Victoria-wide assessment of additional streamflow decline due to hydrological shift observed during the Millennium Drought. In some catchments, the Millennium drought changed how rainfall is converted to runoff which caused additional declines in streamflow on top of what can be attributed just to rainfall deficits. We investigated a large range of potential predictors representing the drivers of this shift using information criteria and multi-model inference, and created a statistical model based on the best-performing predictors. The map we produced characterises the hydrologic resilience to multiyear droughts across Victoria. As we found that the additional streamflow decline was heavily dominated by catchment properties, rather than drought properties, we expect that our findings and the map can provide guidance for other long and persistent periods of drier climate, e.g. under projected climate change, where the local hydrologic shift data are not available. Further research is needed to improve our understanding of the physical mechanisms driving hydrologic shifts and develop physically meaningful models robust under changing conditions. 
Saft et al., Mapping additional streamflow decline due to the shifts in catchment response during the Millennium Drought

\section{ACKNOWLEDGEMENTS}

This study received support from Victorian Water and Climate Initiative (VicWaCI) which was funded by the Victorian Department of Environment, Land, Water and Planning (DELWP). Calculating indices related to catchment properties other than hydroclimatic means and map production for the Figure 4 was done by HARC (Phillip Jordan, David Shepherd) under contract with DELWP. This research was facilitated by Jasmine Errey from DELWP and we thank her for all her help and support. We thank Ilja van Meerveld and Andrew Western for useful advice on potential predictors.

\section{REFERENCES}

Bozdogan, H., 1987. Model selection and Akaike's Information Criterion (AIC): The general theory and its analytical extensions. Psychometrika 52(3) 345-370.

Burnham, K.P., Anderson, D.R., 2002. Model selection and multimodel inference: A practical informationtheoretic approach, 2 ed. Springer, New York.

Chiew, F.H.S., Potter, N.J., Vaze, J., Petheram, C., Zhang, L., Teng, J., Post, D.A., 2014. Observed hydrologic non-stationarity in far south-eastern Australia: implications for modelling and prediction. Stochastic Environmental Research and Risk Assessment 28(1) 3-15.

Chiew, F.H.S., Young, W.J., Cai, W., Teng, J., 2011. Current drought and future hydroclimate projections in southeast Australia and implications for water resources management. Stochastic Environmental Research and Risk Assessment 25(4) 601-612.

Coron, L., Andréassian, V., Perrin, C., Lerat, J., Vaze, J., Bourqui, M., Hendrickx, F., 2012. Crash testing hydrological models in contrasted climate conditions: An experiment on 216 Australian catchments. Water Resources Research 48(5).

Fowler, K., Knoben, W., Peel, M., Peterson, T., Ryu, D., Saft, M., Seo, K.W., Western, A., 2020. Many Commonly Used Rainfall-Runoff Models Lack Long, Slow Dynamics: Implications for Runoff Projections. Water Resources Research 56(5).

Gallant, A.J.E., Gergis, J., 2011. An experimental streamflow reconstruction for the River Murray, Australia, 1783-1988. Water Resources Research 47(4) W00G04.

Hunt, B.G., 2009. Multi-annual dry episodes in Australian climatic variability. International Journal of Climatology 29(12) 1715-1730.

Hurvich, C.M., Tsai, C.-L., 1989. Regression and time series model selection in small samples. Biometrika 76(2) 297-307.

Peterson, T.J., Saft, M., Peel, M.C., John, A., 2021. Watersheds may not recover from drought. Science 372(6543) 745-749.

Potter, N.J., Chiew, F.H.S., 2009. Statistical characterisation and attribution of recent rainfall and runoff in the Murray-Darling Basin, In: Anderssen, R.S., Braddock, R.D., Newham, L.T.H. (Eds.), 18th World Imacs Congress and Modsim09 International Congress on Modelling and Simulation: Interfacing Modelling and Simulation with Mathematical and Computational Sciences. Univ Western Australia: Nedlands, pp. 28122818.

Potter, N.J., Chiew, F.H.S., Frost, A.J., 2010. An assessment of the severity of recent reductions in rainfall and runoff in the Murray-Darling Basin. Journal of Hydrology 381(1-2) 52-64.

Saft, M., Peel, M., \& Peterson, T. (2021). Explaining hydrological shift and non-recovery after prolonged drought. Submitted to Nature Climate Change.

Saft, M., Peel, M.C., Western, A.W., Perraud, J.-M., Zhang, L., 2016a. Bias in streamflow projections due to climate-induced shifts in catchment response. Geophysical Research Letters 43(4) 1574-1581.

Saft, M., Peel, M.C., Western, A.W., Zhang, L., 2016b. Predicting shifts in rainfall-runoff partitioning during multiyear drought: Roles of dry period and catchment characteristics.

Saft, M., Western, A.W., Zhang, L., Peel, M.C., Potter, N.J., 2015. The influence of multiyear drought on the annual rainfall-runoff relationship: An Australian perspective. Water Resources Research 51(4) 24442463.

Trotter L., Saft, M., Peel, M.C., Fowler, K.J.A., 2021 (accepted). "Naïve" inclusion of diverse climates in calibration is not sufficient to improve model reliability. MODSIM International Congress on Modelling and Simulation, Sydney, Australia.

Voorwinde, L., Nathan, R. and Hansen, B., 2003, January. Estimation of the sustainable winter diversions in ungauged Victorian catchments. In 28th International Hydrology and Water Resources Symposium: About Water; Symposium Proceedings (pp. 2-81). Barton, ACT: Institution of Engineers, Australia.

Zhongmiao Wang \& Bruce Thompson (2007) Is the Pearson $r 2$ Biased, and if So, What Is the Best Correction Formula?, The Journal of Experimental Education, 75:2, 109-125, DOI: 10.3200/JEXE.75.2.109-125 